\title{
Risk Management Capability Maturity and Performance of Complex Product and System (CoPS) Projects with an Asian Perspective
}

\author{
Yingtao Ren ${ }^{1}$, Khim Teck $\mathrm{Yeo}^{2}$, and Yingju Ren ${ }^{3}$ \\ ${ }^{1}$ Research Scientist, Manhattan Associates, Inc., 2300 Windy Ridge Parkway Southeast, Atlanta, GA 30339, USA. Email: \\ renyingta098@gmail.com (corresponding author) \\ ${ }^{2}$ Associate Professor, School of Mechanical and Aerospace Engineering, Nanyang Technological University, 50 Nanyang \\ Avenue, Singapore, 639798. Email: mktyeo@ntu.edu.sg \\ ${ }^{3}$ Research Engineer, The Institute of Nuclear and New Energy Technology, Tsinghua University, Beijing 102201, China. \\ Email: renyingju@ hotmail.com
}

Project Management

Received June 6, 2013; received revisions July 12, 2013; September 26, 2013; accepted October 16, 2013

Available online April 24, 2014

\begin{abstract}
Complex Products and Systems (CoPS) are high value, technology and engineering-intensive capital goods. The motivation of this study is the persistent high failure rate of CoPS projects, Asian CoPS provider's weak capability and lack of specific research on CoPS risk management. This paper evaluates risk management maturity level of CoPS projects against a general CoPS risk management capability maturity model (RM-CMM) developed by the authors. An Asian based survey was conducted to investigate the value of RM to project performance, and Asian (non-Japanese) CoPS implementers' perceived application of RM practices, their strengths and weaknesses. The survey result shows that higher RM maturity level leads to higher CoPS project performance. It also shows project complexity and uncertainty moderates the relationship between some RM practices and project performance, which implies that a contingency approach should be adopted to manage CoPS risks effectively. In addition, it shows that Asian CoPS implementers are weak in RM process and there are also rooms for improvement in the softer aspects of organizational capabilities and robustness.
\end{abstract}

Keywords: Complex Products and Systems (CoPS), capability maturity model (CMM), complexity, project risk management (PRM), Asian perspective.

\section{Introduction}

Complex products and systems (CoPS) are defined as capital-intensive products, systems, constructs and networks which involve a lot of engineering and technology (Hobday, 1998). Examples of CoPS include large telecommunication systems, aero and spatial systems, intelligent building, power plant, petrochemical complex, offshore oil platform, wafer fabrication plant, jumbo aircraft, rapid transit train system, complex software and information systems, etc. They are usually developed in a single project. CoPS are composed of various components, including hardware and embedded software, and often involve inter-disciplinary inputs. The development and innovation of CoPS involve many related organizations and parties, such as systems integrators, owners, operators, major equipment suppliers, prime and sub-contractors, and often, the government regulatory agencies.

CoPS are important to the national economy because they not only form a significant portion of industrial production, but also they are vital capital investments contributing to the production capacity of the nation (Hobday and Rush, 1999). For example, the baggage handling system is a critical component of both domestic and international airports; the modern power plants generates electricity for industrial and civilian use; and the wafer fabrication plants serve as the foundation of the semiconductor. Rosenberg (1976) suggested that capital goods were key entry points for the adoption of new technology in the production systems.

In this paper we study CoPS risk management practices from an Asian perspective. We first review related literature and identify research gaps. Then we briefly review a comprehensive RM-CMM for CoPS projects. We build the research model and formulate hypotheses based on the model. After that we report our findings from the data analysis of a questionnaire. The contributions and implications of the key findings are discussed. Finally we conclude the paper and identify the limitations and future work.

\section{Key Literature Review}


In this section, we review the literature related to perceived value of project risk management, challenges of Asian CoPS providers, the contingency approach for Project Management (PM) and Project Risk Management (PRM), and organizational and human factors in PRM.

\subsection{Value of Project Risk Management (PRM)}

One of the motivations of the research is the persistent high failure rate of CoPS projects (either challenged or impaired) against expectation over the recent decades. Complex capital goods are often characterized by large variations in their development outcomes, with larger and more complex systems showing higher levels of failure (Morris, 1990; Miller and Lessard, 2000; Lai, 2010). The IMEC program carried out by Miller and Lessard (2000) showed that of the 60 Large Engineering Projects (LEP) studied only $45 \%$ achieved most of the project objectives, and $20 \%$ was abandoned after large amount of funds were wasted. Based on a survey of $700 \mathrm{CoPS}$ providers, the success rate of CoPS development was only 35\% (Lai, 2010).

More and more organizations realized the value of a structure way to manage their risks and began to take advantage of proactive risk management (Yeo and Ren, 2009). The objectives of risk management include not only the usual time-cost-quality triangle, but also other objectives, such as profitability, other business benefits such as competitive edge, market, technology acquisition, regulatory compliance, and environmental impact. Failure to manage risks effectively will inevitably result in failure to meet some or all of these objectives, and incur losses as a consequence. Conversely, a comprehensive risk management framework should increase the probability of meeting project objectives, or even surpassing the original objectives by exploiting emerging opportunities.

Indeed, a lot of researchers believed that risk management is the most important factor to ensure project success (Chapman and Ward, 2003; Kerzner, 2009). In a survey to project management practitioners (Whittaker, 1999), the most common failure factors for information technology projects included inadequate risk management, a poor project plan, a weak business case, and lack of top management involvement and support. Poor risk management was ranked the highest among these factors. Despite the importance of risk management, the quality of project risk management ranges from very poor (most common practice) to very good (fully embracing all relevant uncertainty and risk efficiency) (Chapman and Ward, 2011). Therefore we can conclude that that risk management is a vital area for the management of CoPS projects.

There are only few empirical researches on the usefulness of risk management in projects. In an attempt to answer the question whether organizations that employ formal risk management practices outperform those that do not, 175 members of Project Management Institute (PMI) Risk Management Specific Interest Group were surveyed (Ivory and Alderman, 2005). The results show that Risk management does make a difference in contributing to project performance. Stronger senior management support for formal RM efforts correlates with actual RM practices and regular risk monitoring, and these in turn correlate with a higher reported frequency of project success. Zwikael and Ahn (2011) examined the effectiveness of current risk management practices to reduce project risk using a multinational, multi-industry survey across different scenarios and cultures. Results of this study showed that project context-industry and country where a project was executed-significantly impacted perceived levels of project risk, and the intensity of risk management processes. Oyewobi et al. (2012) evaluated the impact of estimating risk on contractor's tender sum with a view of ensuring efficient delivery of projects in Nigeria. They recommended that construction professionals should identify and adequately quantify risk factors related to project estimating. One limitation of these studies is that they are for generic projects. The findings may not be generalizable to CoPS projects.

\subsection{Challenges to Asian CoPS Implementers}

CoPS is still an area where East Asian non-Japanese companies have not made considerable advancement into Western markets, and Western firms' dominance in CoPS market and capability ensure the enduring strength of leading CoPS firms in the future (Ren and Yeo, 2006). It is essential for the Asian countries to close the gap with their Western counterparts in this important area. The twin core competencies in CoPS providers such as Boeing and Airbus, are complex system engineering integration and mega-program management, and a comprehensive risk management capability is a core component of these core competencies. For example, Singapore can develop and enhance its system integration competence in many infrastructure construction projects such as water processing plants, rapid transit systems, and wafer fabrication plants.

We need an effective response to close the gap, which constitute an important part of the overall research question. The efforts by Asian countries such as China and South Korea to enhance the CoPS development capability were studied (Zhang and Igel, 2001; Hwang, 2000). There were challenges when the firms in these countries served as sub-contractors of systems integrators of Western countries. To fully support their domestic CoPS market, there is an urgent need for Asian countries to nurture their indigenous large-scale system integrators, with the view to export CoPS services to the global markets. Another situation where the challenges also occur is when governments support particular CoPS industries for the development of their national capability. Asian nations like China, South Korea, Singapore, Malaysia and India, all have high aspiration to achieve a developed nation status in 10 to 20 years. However there are few researches that focus specifically on the risk management of Asian CoPS providers. At the present time, little is known about the maturity level of risk management practices of Asian CoPS providers, and what they can do to improve their RM maturity level.

\subsection{Contingency Approach Needed for PM and PRM}

The generic risk management processes and techniques are well defined in the Project Management Body of Knowledge (PMBOK) (PMI, 2008) and the Project Risk Analysis and Management (PRAM) (Chapman and Ward, 2003). However, projects differ in many aspects, and there is a need to apply different risk management and project management style to different types of projects. To address differences among projects, Shenhar (1998) developed a project classification model according to two dimensions: technological uncertainty and system scope. The systems scope captures project complexity. Projects 
are categorized into low-, medium-, high-, and super hightechnology according to the first dimension, and they are categorized into assembly, system, and array from the perspective of the second dimension. An analysis based on a questionnaire survey revealed that more risk management, system integration and configuration management should be conducted when project technological uncertainty and complexity are high. Shenhar and Dvir (2007) added two other dimensions to a diamond-shaped framework to help managers distinguish among projects according to four dimensions: Novelty, Technology, Complexity, and Pace (NTCP). A case study of NASA's Mars Climate Orbiter loss by Sauser et al. (2009) showed that different projects have different characteristics and should be managed in different ways. Yeo (1995) developed a risk management framework for technology acquisition projects based on soft system methodology (SSM). Depending on the availability of well-defined mental models, at one end of the risk framing spectrum was dynamic learning and planning from ambiguity, and at the other end was relative certainty. In the middle was controlled uncertainty. De Meyer et al. (2002) identified four major types of uncertainty: variation, foreseen uncertainty, unforeseen uncertainty, and chaos. He proposed different leadership and management styles for different types of uncertainty. Crawford and Pollack (2004) identified seven dimensions of hardness and softness of projects: goal clarity, goal tangibility, success measures, project permeability, number of solution options, participation and practitioner role, and stakeholder expectations. A later study suggested different project management approaches were appropriate for different types of project (Crawford et al., 2005). Müllera and Turner (2007) showed that the project manager's leadership style influenced project success, and different leadership styles were appropriate for different types of project.

The same concept of adaptability and contingency applies to project risk management. It is unrealistic to apply a generic risk management process and style to all project types. For example, Raz et al. (2002) found that risk management practices were applied more in projects with higher technological uncertainty. Chapman and Ward (2003) suggested that formal risk management processes were more applicable to highly risky major projects, and a structured and formal risk management process helped organizations gain competitive advantage. There are still gaps in this area. First, these RM studies are for general projects. Second, the effect of project characteristics on the contingency approach is not comprehensively studied. For example, the effect of requirement uncertainty was not considered.

\subsection{Organizational and Human Factors in PRM}

$\mathrm{RM}$ processes themselves are not enough in addressing project risks, organizational and human aspects such as culture, institutional arrangements (e.g., partnership), stakeholder management, risk sharing and allocation, and opportunity management also needs to be considered. Chapman and Ward (2008) developed a balanced incentive and risk sharing (BIARS) contract framework to facilitate choosing the appropriate form of contract. They conclude that it is practical and advantageous to integrate contract choice decisions and other aspects of a best practice approach to manage risk and uncertainty. Ward and Chapman (2008) emphasized stakeholder management to address uncertainty. A generic project uncertainty management process framework, called SHAMPU (Shape, Harness, and Manage Project Uncertainty) process, was employed to provide a structure for a review of approaches to analyzing stakeholders and related uncertainty management issues. Olsson (2007) presented three major factors needed for managing opportunities: the ability of the project manager to develop a holistic view within the project, the organizational support and interest, and the ability to understand how other organizations affect the project objectives. Marrewijk et al. (2008) conducted a comparative study of two megaprojects in Netherlands and Australia. They conclude that project design and project cultures play a role in determining how managers and partners cooperate to achieve project objectives to a greater or lesser extent. Abednego and Ogunlana (2006) studied public-private partnership (PPP) procurement system in a tollway project of Indonesia. They first identified the perceived proper risk allocation of each participating partner, and then defined good project governance based on that. At last this notion was used to get proper risk allocation to improve the performance of the tollway projects. Despite these studies, there is still lack of quantitative studies of how organization factors such as risk management culture and stakeholder coalition in CoPS projects affect project performance (e.g., through a survey and statistical analysis).

\section{Research Gap and Research Objective}

From the literature review, we can see that studies on PRM abound, but there are relatively fewer studies that have focused specifically on risk management capability maturity, its relation to the performance of CoPS projects, and from an Asian perspective. None of them measure RM practices against a comprehensive CoPS-RM-CMM model. The objective of this study is to investigate some of the unanswered questions in the current literature. More specifically, we try to answer the following questions:

- What are the effects of risk management capability maturity level on the performance of CoPS projects?

- Does a contingency approach in RM is adopted in practice? What are the moderating effect of project complexity and uncertainty?

- What is the current level of risk management capability maturity of Asian CoPS producers (mainly Singapore and China)? What are the relatively weak areas and how to address them?

- What is the perceived importance of RM for improving the capability of CoPS providers?

We will also compare our results with general PRM studies such as Raz et al. (2002) to identify the commonalities and differences.

\section{Risk Management Capability Maturity Model for CoPS Projects}

A Risk Management Capability Maturity Model for CoPS projects (CoPS-RM-CMM) was developed by Yeo and Ren (2009). For the sake of completeness, we briefly introduce the model in this section. The RM capability maturity is perceived and measured in terms of both hard aspects (such as system, process, and technology) and soft aspects (such as human factors including leadership and 
culture). The CoPS-RM-CMM is built on five levels of capability maturity: (1) Ad-hoc; (2) Initial; (3) Defined; (4) Managed; and (4) Optimizing. It is also built on three key capability areas, namely organizational, process, and technological capability. Capability Maturity Model (CMM) has its origin in the Software Engineering Institute (SEI)'s software process capability improvement model (SEI, 1993). CMM has been evolved to Capability Maturity Model Integration (CMMI), which is a process improvement approach that provides organizations with the essential elements of effective processes (SEI, 2002). CMMI helps integrate traditionally separate organizational functions, set process improvement goals and priorities, provide guidance for quality processes, and provide a point of reference for appraising current processes.

The RM-CMM architecture is shown in Fig. 1 which simultaneously deals with the capability area, maturity level and type of risk, and in two broad tiers. The first and foundational tier is to achieve increasing "security" with systems capability in terms of process and technology applications, and the second and higher tier on increasing "robustness" with softer aspects of organizational and leadership capability.

In this model the authors introduce two broad categories of risk as the known risk and emergent risk. The strategy is to build both "security" to deal with known and internal risks, and "robustness" to emergent and largely external risks. Security is based on a mechanistic management system, while robustness is mainly based on the emergence management style and the dealing with the hard-to-predict risks. The model is based on the change management framework. It addresses issues in the organizational contexts (internal and external), process and content, guided by strategic and project level performance measurement requirements. The model defines what constitute risk management capabilities, and provides guidelines to allow diagnosis of current levels of risk management capability maturity.

In the above RM-CMM architecture, security is associated with key capability areas of project risk management systems and processes and with the supports of technology. These capability areas serve as the cornerstone to address predictable and internal risks. Robustness is associated with key capability areas such as culture, stakeholder coalition, corporate and project leadership, organizational structure and supports, as these form the foundation for the "softer" capabilities to deal with relatively unpredictable and uncontrollable risks. This is illustrated in Fig. 2.

We chose this model because it has a strong theoretical basis from change management, complexity theory and PRM. In addition, it is specifically designed for CoPS projects. It explicitly specifies how to deal with the emergent and unpredictable risks, which is very common in CoPS projects. It also consists of measuring items for each capability which helps identification of strengths and weaknesses.

The limitation of this model is that there is no direct empirical support that the proposed RM constructs correlates positively with CoPS project performance, and the structure that known risks and emergent risk should be mainly managed by security and robustness related constructs respectively.

\section{RM Capability Maturity Constructs}

5.1. Characterizing Project Complexity and Uncertainty

\section{CoPS-RM-CMM}

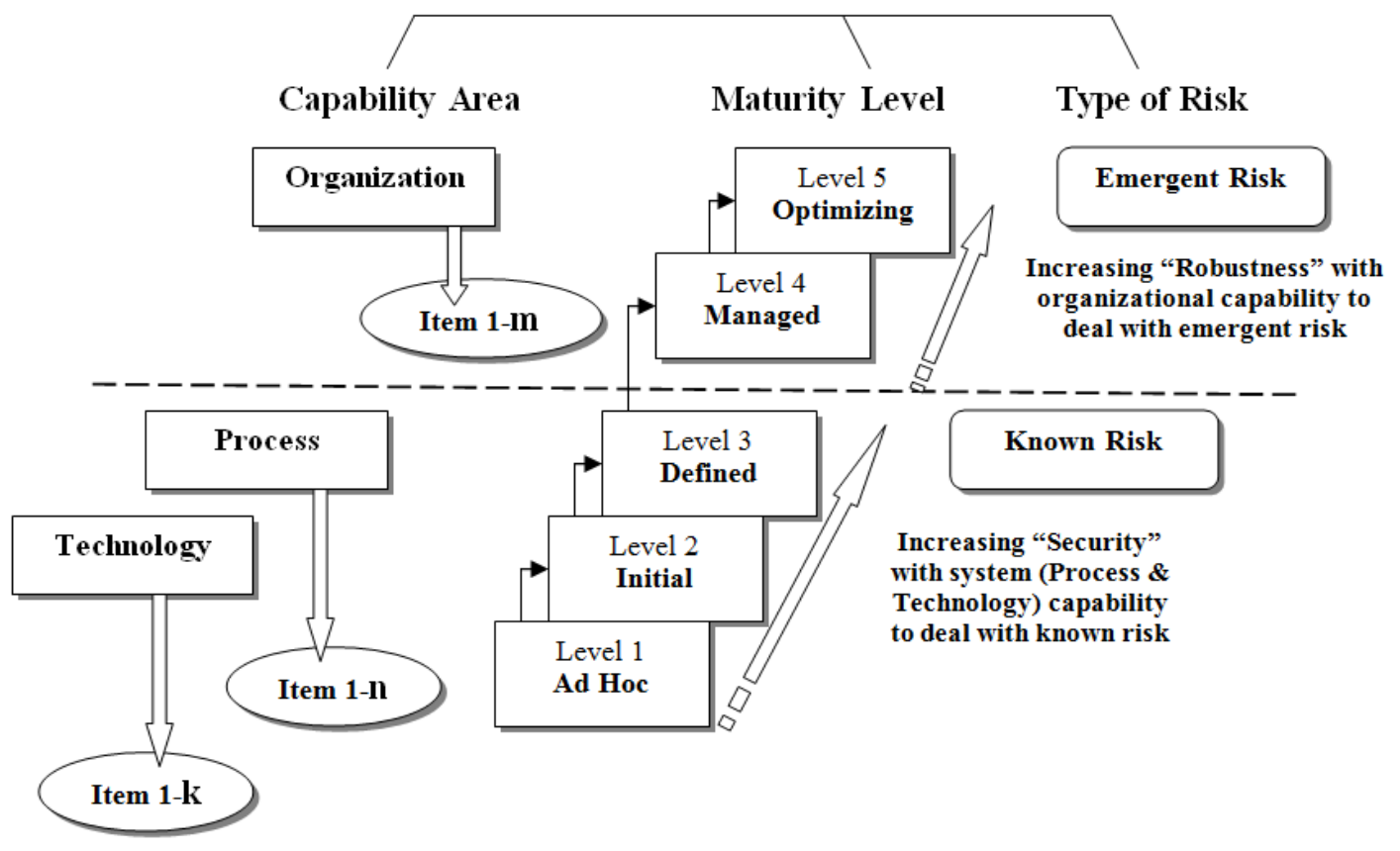

Fig. 1. A CoPS-RM-CMM architecture (source: Yeo and Ren (2009), reprinted with permission) 


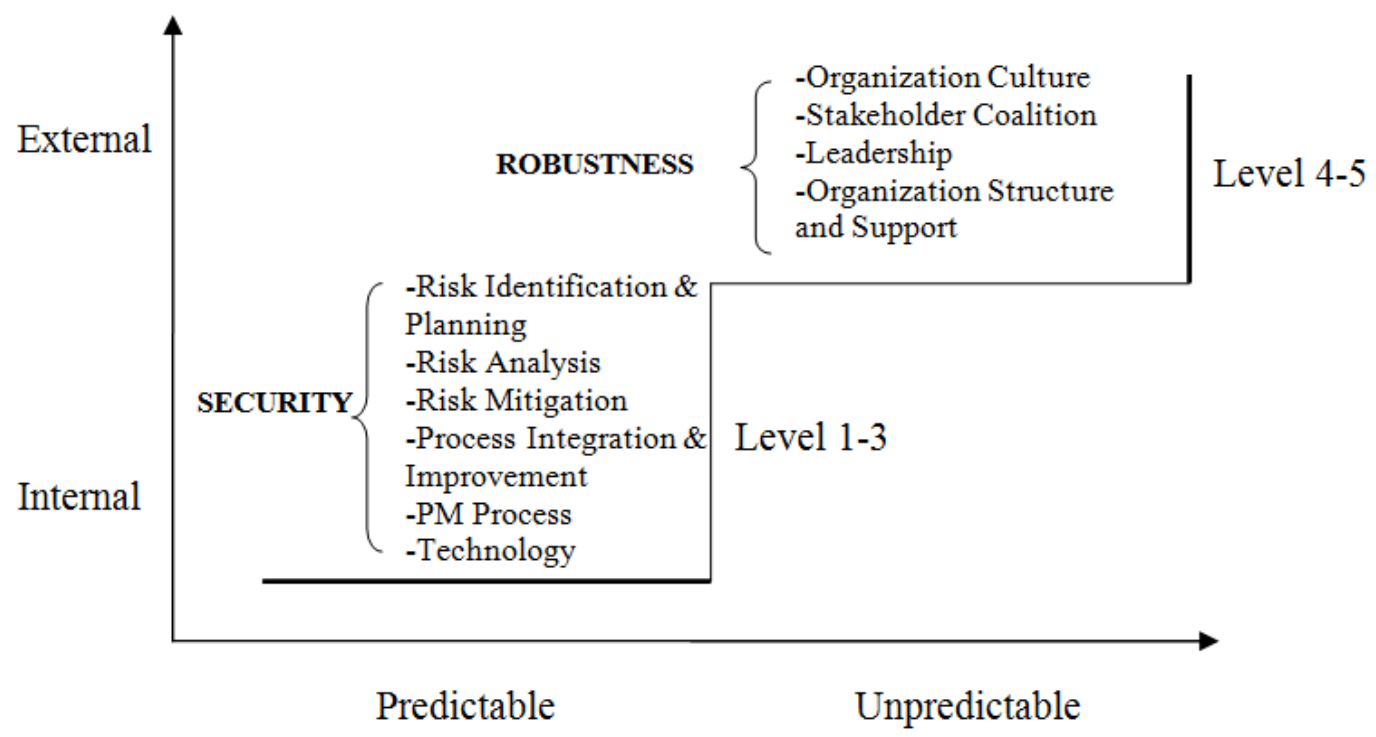

Fig. 2. Robustness, security and key capability areas (source: Yeo and Ren (2009), reprinted with permission)

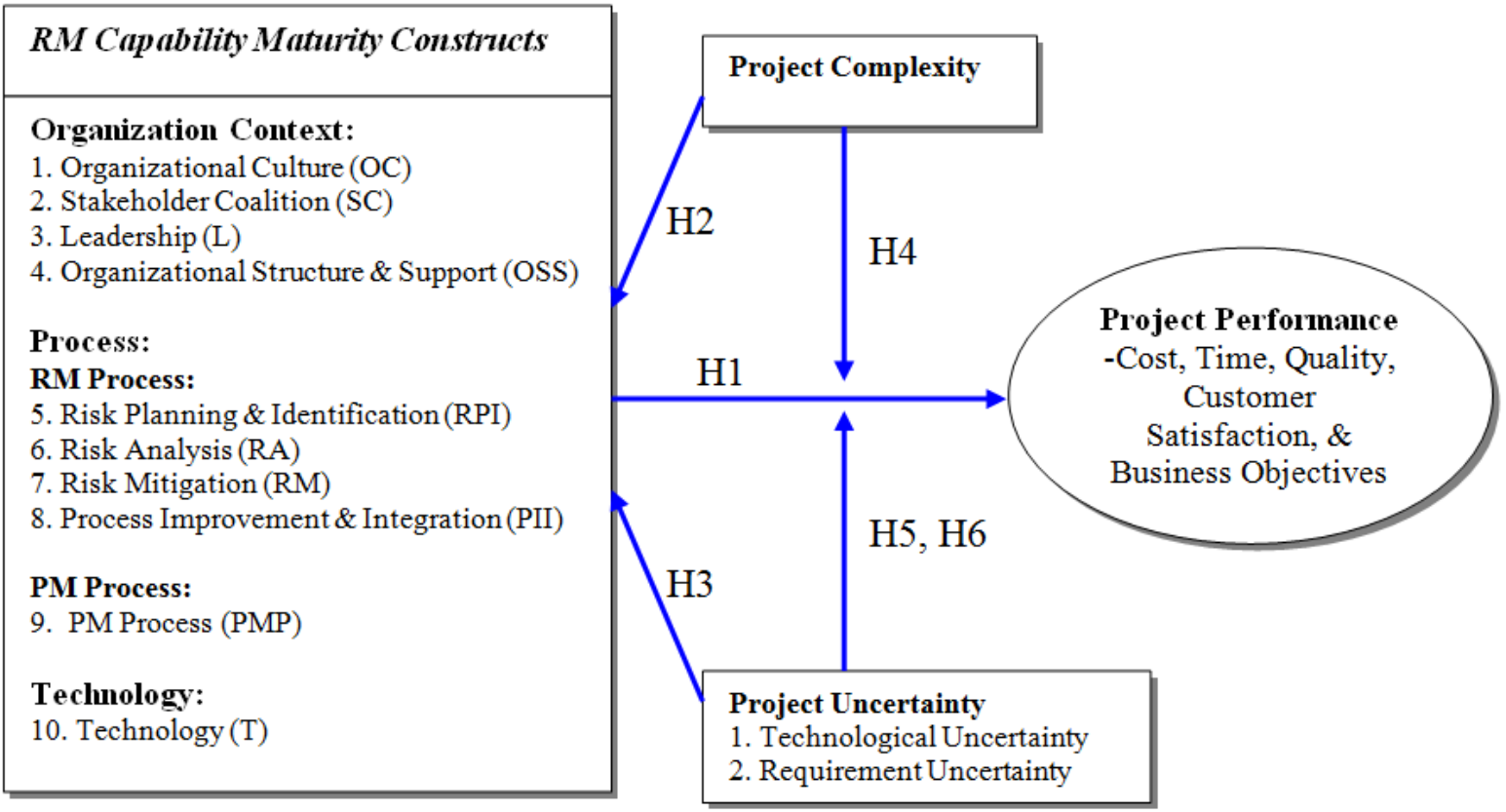

Fig. 3. The research model

Following prior literature reviews in task complexity (Wood, 1986), project complexity (Williams, 1999), Information System Development Project (ISDP) complexity (Xia and Lee, 2005), CoPS definition (Hobday, 1998), complex systems failures (Ivory and Alderman, 2005), we define CoPS project complexity as a function of the number of project components and the strength of interrelationships between the components, and project uncertainty due to incomplete information and dynamic changes in project components and their relationships. Both project complexity and uncertainty can be further broken down into organizational and technological dimensions (Baccarini, 1996).

Taken together, the overall CoPS project complexity is defined as a multidimensional construct consisting of four components: organizational complexity, task complexity, technological uncertainty and requirement uncertainty. The measurement items of CoPS project complexity are summarized in Table 1. Our focus is on factors closely related to the project; therefore macro-environmental factors such as political, social and economic factors are excluded.

\subsection{The Research Model and Hypotheses}

The research model shown in Fig. 3 illustrates the relationships between ten RM capability maturity constructs grouped under organization, process and technology and aspects of project performance. The abbreviations of the constructs are shown in the figure. Each of the RM capability construct will be described by its constituent items as listed in Table A.1 of appendix. The details of how these items are derived are presented in Yeo and Ren (2009). These RM practices or items are 
grouped under the ten RM-CMM constructs and converted into a set of statements applicable to a questionnaire survey.

Aspects of project performance measurement include project schedule (time), budget (cost), technical performance requirements (quality), customer satisfaction, and business objectives. The responses are measured on a five-point Likert (1 5), where 1 stands for "very poor" and 5 stands for "very good". The overall performance is the mean of the scores of the five items.

Different CoPS implementers have different levels of RM capability maturity and various levels of achievement at project and business performance. RM-CMM is designed with the assumption that CoPS implementers with higher RM capability will manage risk and uncertainty more effectively, and better achieve project objectives with less stress and conflicts, and hence higher overall project performance as illustrated in Fig. 3. This suggests the hypothesis 1 to be tested:

Hypothesis 1 (H1): Risk management capability maturity level correlates positively with project performance.

We also want to test whether there is a contingency approach in risk management practices in CoPS projects, as evidenced by Raz et al. (2002). We argue that as project complexity and uncertainty increases, project practitioners tend to undertake more risk management activities. Therefore we have Hypothesis 2 and Hypothesis 3:

Hypothesis 2 (H2): CoPS Project Complexity correlates positively with Risk Management Capability Maturity Level.

Hypothesis 3 (H3): CoPS Project Uncertainty correlates positively with Risk Management Capability Maturity Level.

In addition, we test whether RM is more useful in highly complex and uncertain projects, as suggested by Raz et al. (2002) and Chapman and Ward (2003).
Therefore we have Hypotheses 4-6. We break down Project Uncertainty into Technological Uncertainty and Requirement Uncertainty.

Hypothesis 4 (H4): When CoPS Project Complexity is higher, the RM capability maturity has a greater positive effect on Project Performance.

Hypothesis 5 (H5): When CoPS Technological Uncertainty is higher, the RM capability maturity has a greater positive effect on Project Performance.

Hypothesis 6 (H6): When CoPS Requirement Uncertainty is higher, the RM capability maturity has a greater positive effect on Project Performance.

\section{RM Capability Maturity Factors}

\subsection{Survey Data Collection}

The research survey has a special interest to investigate the perception and perceptive of project managers operating in an Asian environment concerning effective risk management of CoPS projects. The survey questionnaires were distributed to a large sample of project managers, project leaders and senior managers with experience in implementing complex projects. The respondents are mainly located in Singapore, though a small sample of respondents was obtained from China who were surveyed using a translated version of the questionnaire. Respondents are asked to indicate the level of applicability of the items relating to RM capability maturity in one recent CoPS project that they have personally involved. To make sure the respondent will choose a CoPS project, the definition of CoPS projects is provided in the questionnaire. In addition, we intentionally send the questionnaire forms to organizations capable of performing CoPS projects. The responses are measured on a five-point Likert scale from 1 to 5 in applicability of the listed risk management practices in their respective reference projects. We conducted a pilot test, in which the initial questionnaire was previewed by several researchers and senior project managers, and revised according to their comments.

Table 1. Characterizing project complexity and uncertainty

\begin{tabular}{ll}
\hline & \multicolumn{1}{c}{ Characterizing Items } \\
\hline & Organizational Complexity: \\
& PC1: Number of external contractors and vendors (Wood, 1986) \\
& PC2: Intensity of involvement of internal functions and departments (Wood, 1986) \\
& Task complexity: \\
& PC3: Work Breakdown Structure (WBS) levels \\
Project Complexity & PC4: Product Breakdown Structure (PBS) levels, reflecting the hierarchy of product (Hobday, \\
1998) & PC5: Degree of customization of the product/system (Hobday, 1998) \\
& PC6: Degree of inter-connection of system components/with external systems (Wood, 1986) \\
& PC7: Variety of distinct knowledge and skills required (Hobday, 1998; Williams, 1999) \\
& Technological Uncertainty: \\
& PU1: Degree of technological novelty (Hobday, 1998) \\
& Requirements Uncertainty: \\
& PU2: Frequency of change in client/user requirements \\
& PU3: Difficulty of meeting regulatory requirements (Hobday, 1998; Williams, 1999) \\
PU4: Ambiguity in project goals and requirements (Hobday, 1998) \\
PU)
\end{tabular}


Table 2. The relationship between RM-CMM constructs and Project Performance

\begin{tabular}{lc}
\hline \multicolumn{1}{c}{ RM-CMM constructs } & Project Performance \\
\hline Organizational Culture (OC) & $0.339^{* * *}$ \\
Stakeholder Coalition (SC) & $0.512^{* * *}$ \\
Leadership (L) & $0.488^{* * *}$ \\
Organization Structure \& Support (OSS) & $0.441^{* * *}$ \\
Risk Planning \& Identification (RPI) & $0.331^{* * *}$ \\
Risk Analysis (RA) & $0.300^{* * *}$ \\
Risk Mitigation (RM) & $0.298^{* *}$ \\
Process Improvement \& Integration (PII) & $0.330^{* * *}$ \\
Project Management Process (PMP) & $0.478^{* *}$ \\
Technology (T) & $0.593^{* *}$ \\
\hline$* * * \mathrm{p}<0.001 * * \mathrm{p}<0.01 * \mathrm{p}<0.05$ &
\end{tabular}

$* * * \mathrm{p}<0.001,{ }^{* *} \mathrm{p}<0.01,{ }^{*} \mathrm{p}<0.05$

Table 3. The correlation between Project Complexity and Uncertainty and RM-CMM constructs

\begin{tabular}{lccc}
\hline \multicolumn{1}{c}{ RM-CMM constructs } & Project Complexity & Technological Uncertainty & $\begin{array}{c}\text { Requirement } \\
\text { Uncertainty }\end{array}$ \\
\hline Organizational Culture (OC) & $0.488^{* * *}$ & $0.213^{*}$ & $0.210^{*}$ \\
Stakeholder Coalition (SC) & $0.386^{* * *}$ & 0.147 & $0.230^{* *}$ \\
Leadership (L) & $0.332^{* * *}$ & 0.167 & 0.144 \\
Organization Structure \& & $0.387^{* * *}$ & 0.131 & $0.179^{*}$ \\
Support (OSS) & & & \\
Risk Planning \& & $0.442^{* * *}$ & $0.215^{*}$ & 0.159 \\
Identification (RPI) & $0.375^{* * *}$ & 0.168 & 0.136 \\
Risk Analysis (RA) & $0.412^{* * *}$ & 0.110 & 0.033 \\
Risk Mitigation (RM) & $0.447^{* * *}$ & $0.253^{*}$ & $0.231^{* *}$ \\
Process Improvement \& & $0.500^{* * *}$ & $0.174^{*}$ & $0.285^{* *}$ \\
Integration (PII) & $0.387^{* * *}$ & 0.127 & $0.267 * *$ \\
Project Management Process & & & \\
(PMP) & & & \\
Technology (T) & & &
\end{tabular}

$* * * \mathrm{p}<0.001, * * \mathrm{p}<0.01, * \mathrm{p}<0.05$

A total of 650 survey forms were sent with 152 responses and of which 133 were useable, yielding a response rate of $20.5 \%$. Both mail survey and Internet online survey were conducted. Over $70 \%$ of the respondents are at senior management level. Of all the references project of the respondents, $45.9 \%$ are construction projects (railway projects, complex buildings, etc.), $18.8 \%$ are information/software system projects, $8.3 \%$ are manufacturing/production system projects, and others are $27 \%$.

\subsection{Validity and Reliability of the Constructs}

Before conducting data analysis, the validity and reliability of the constructs are tested. Confirmatory factor analysis is a common technique to verify the validity of the constructs (McDonald, 1985). Our analysis shows that Project Complexity, RM-CMM constructs, and Project Performance are all loaded into a single factor except Project uncertainty, which are loaded into two factors:
Technological Uncertainty (including item PU1) and Requirements Uncertainty (including PU2, PU3, and PU4). Therefore in later analysis related to Project Uncertainty we differentiate the two factors. Reliability is one of the most critical elements in assessing the quality of the construct measures (Churchill, 1979). The reliability of the constructs is tested using Cronbach's Alpha method. Cronbach's Alpha determines the internal consistency or average correlation of items in a survey instrument to gauge its reliability, and a value of 0.70 or higher is considered acceptable (Cortina, 1993). It is found that all Alpha values are above 0.80 , which means the internal consistency is very high.

\subsection{Testing of Hypotheses}

The correlation coefficients between RM-CMM constructs and project performance are shown in Table 2. We can see that all constructs of CoPS-RM-CMM are significantly correlated with project performance. While correlation 
relationship does not prove causality, project risk management, like any other project management activity, can be considered as an independent variable and project performance as a dependent variable (Raz et al., 2002). Therefore we can conclude that higher RM capability maturity leads to higher project performance. The basic assumption of the CoPS-RM-CMM structure is that higher RM capability maturity is associated with managing various risks better, which leads to higher project performance. The test results verify this assumption, thus the basic structure of the CoPS-RM-CMM is verified. It is also verified that both Security (including RPI, RA, RM, PII, PMP, and T) and Robustness (including OC, SC, L, and OSS) lead to higher project performance. This validates the claim of CoPS-RM-CMM that both security and robustness are important to project performance.

The results of the testing Hypothesis 2 and 3 are shown in Table 3 . It can be seen that the correlation coefficients between Project Complexity and RM-CMM constructs are all statistically significant. Therefore $\mathrm{H} 2$ is supported. It implies that in projects with higher complexity, project practitioners tend to conduct more risk management practices to cope with the increasing complexity.

For Technological Uncertainty, the correlation coefficients between it and 4 RM Capability Maturity constructs (OC, RPI, PII, and PMP) were statistically significant, while others were not. This implies when Project Uncertainty increases, project practitioners tend to build higher level of OC, RPI, PII, and PMP to cope with increasing uncertainty.

For Requirement Uncertainty, the correlation coefficients between it and 6 RM Capability Maturity constructs (OC, SC, OSS, PII, PMP, and T) were statistically significant, while the correlation coefficients between Project Uncertainty and 4 RM capability maturity constructs (L, RPI, RA, and RM) were not statistically significant. This implies when Requirement Uncertainty increases, project practitioners tend to build higher level of OC, SC, OSS, PII, PMP and T. But higher project uncertainty was not associated with higher RM process (RPI, RA, and RM). This is probably due to the difficulty of conducting accurate risk identification, risk analysis and risk mitigation when the situation is uncertain and changing. It is also possible that RM process is not effective when project uncertainty is higher.

From above analysis, we see $\mathrm{H} 3$ is partially supported. Overall there is indeed a contingency approach in practice where more risk management practices (though not all capability areas) are applied in CoPS projects with higher complexity and uncertainty.

\subsection{Moderating effect of project complexity and uncertainty}

We explore the moderating effect of project complexity and uncertainty on the relationship between RM-CMM constructs and project performance. Chow's test (Chow, 1960) is to test the equality between two coefficients in two linear regressions. It is a classical test for structural change. In this paper, Chow's test was used to test whether two subgroups are significantly different with respect to the correlation coefficient between each RM-CMM construct and Project Performance. Project Complexity or Project Uncertainty scores were used to divide the sample into three groups: low-, medium-, and highcomplexity/uncertainty. We compare the low complexity/uncertainty group and the high complexity/uncertainty group.

Table 4. Comparison of regression coefficients between two sub-groups of project complexity

\begin{tabular}{|c|c|c|c|c|}
\hline RM-CMM constructs & $\begin{array}{c}\text { Project Performance } \\
\text { (Low Complexity, } \\
\text { N1=38) }\end{array}$ & $\begin{array}{c}\text { Project Performance } \\
\text { (High Complexity, } \\
\text { N2=44) }\end{array}$ & $\mathrm{F}$ & $\begin{array}{c}\text { Level of } \\
\text { Significance }\end{array}$ \\
\hline Organizational Culture (OC) & -0.032 & $0.582 * * *$ & 4.309 & $0.017 * * *$ \\
\hline Stakeholder Coalition (SC) & $0.395^{*}$ & $0.534 * * *$ & 0.067 & 0.935 \\
\hline Leadership (L) & 0.264 & $0.555^{* * *}$ & 3.486 & $0.035 * *$ \\
\hline $\begin{array}{l}\text { Organization Structure \& } \\
\text { Support (OSS) }\end{array}$ & 0.198 & $0.493 * *$ & 0.677 & 0.511 \\
\hline $\begin{array}{l}\text { Risk Planning \& } \\
\text { Identification (RPI) }\end{array}$ & 0.211 & $0.363 *$ & 0.101 & 0.904 \\
\hline Risk Analysis (RA) & $0.333^{*}$ & $0.288 *$ & 0.310 & 0.950 \\
\hline Risk Mitigation (RM) & 0.115 & $0.388 *$ & 2.324 & 0.105 \\
\hline $\begin{array}{l}\text { Process Improvement \& } \\
\text { Integration (PII) }\end{array}$ & 0.175 & $0.364 *$ & 0.145 & 0.866 \\
\hline $\begin{array}{l}\text { Project Management Process } \\
\text { (PMP) }\end{array}$ & $0.334^{*}$ & $0.504 * * *$ & 0.876 & 0.421 \\
\hline Technology $(\mathrm{T})$ & $0.644 * * *$ & $0.605 * * *$ & 0.355 & 0.702 \\
\hline
\end{tabular}


Table 4 shows the comparison of regression coefficients between two sub-groups of project complexity. $\mathrm{N} 1$ and $\mathrm{N} 2$ are the sample sizes of the respective groups. From the table, we can see that for $\mathrm{OC}$ and $\mathrm{L}$, there is a significant difference between the two regression coefficients. When complexity is low, the two correlation coefficients are not significant, while when complexity is high they are significant. This implies that when complexity is low, building and open culture and democratic style leadership does not help in improving project performance. However, when complexity is higher, they become more important. For other constructs, the differences in regression coefficients are not significant, but the pattern is consistent: all constructs remains important (for SC, RA, PMP and T) or become more important (for OSS, RPI, RM, PII) when Project Complexity becomes higher. Generally we can conclude that Project Complexity does moderate the relationship between some RM capability maturity constructs and Project Performance. When projects become more complex, all constructs become more or equally important for project success. In particular, the importance of organization culture and leadership increases. Therefore, $\mathrm{H} 4$ is partially supported.

Chow's test results for Technological Uncertainty are shown in Table 5. It can be seen that, for Robustness related constructs, OC, L, and OSS have significantly greater positive effect on Project Performance. Only SC does not have a greater positive effect on Project Performance $(p>0.05)$. For Security related constructs, RM Process (including RMI, RA, RM, PII) and PM process all have significantly greater positive effect on Project Performance when Technological Uncertainty is high. Only $\mathrm{T}$ has significantly lower positive effect on Project Performance. This is because other constructs have relatively greater positive effect on Project Performance. Therefore, H5 is supported.

The test results imply that, when Technological Uncertainty increases, Robustness becomes more important or at least equally important (for Stakeholder Coalition). In the meanwhile, systematic RM Process and PM process also become more effective. The role of Technology remains important.

The results of Chow's test for Requirement Uncertainty are shown in Table 6. It can be seen that when Requirement Uncertainty is low, there is a significantly positive relationship between RM process (RPI, RA, RM, and PII) and Project Performance. However, when Requirement Uncertainty is high, there is no significant relationship between them. For these four RM process constructs, the differences in regression coefficients are significant $(\mathrm{p}<0.05)$ or almost significant $(\mathrm{p}<0.10)$. This implies that systematic RM process is not very effective when Requirement Uncertainty is high. For other constructs, the differences in regression coefficients are not significant. Therefore, H6 is not supported. Instead, the other direction is supported for RM process. In lower requirement uncertainty projects, $\mathrm{RM}$ process is more effective.

In addition, we noticed that for projects with higher requirement uncertainty, the correlation between constructs of robustness and project performance is higher than the correlation between constructs of security and project performance. This implies that in highly dynamic projects with emergent risks from requirement uncertainty (including objective ambiguity, requirement changes, and regulatory uncertainty), organizational robustness tends to play a bigger role than security. These findings justified that robustness constructs are put in the higher level of the model (Fig. 1). What is more, since risks originated from complexity and technological novelty are mostly predictable, and risks originated from requirement uncertainty (including objective ambiguity, requirement changes, and regulatory uncertainty) are mostly unpredictable, the test results verified Fig. 2 that security is mainly built to deal with predictable risks, and Robustness is mainly built to deal with unpredictable risks.

Table 5. Comparison of regression coefficients between two sub-groups for Technological Uncertainty

\begin{tabular}{|c|c|c|c|c|}
\hline RM-CMM constructs & $\begin{array}{l}\text { Project Performance } \\
\text { (Low Technological } \\
\text { Uncertainty, N1=44) }\end{array}$ & $\begin{array}{l}\text { Project Performance } \\
\text { (High Technological } \\
\text { Uncertainty, N2=45) }\end{array}$ & $\mathrm{F}$ & $\begin{array}{c}\text { Level of } \\
\text { Significance }\end{array}$ \\
\hline Organizational Culture (OC) & 0.276 & $0.486 * *$ & 4.548 & $0.013 *$ \\
\hline Stakeholder Coalition (SC) & $0.490 * *$ & $0.463 * *$ & 2.492 & 0.089 \\
\hline Leadership (L) & 0.296 & $0.551 * * *$ & 4.263 & $0.017^{*}$ \\
\hline $\begin{array}{l}\text { Organization Structure \& } \\
\text { Support (OSS) }\end{array}$ & 0.235 & $0.539 * * *$ & 3.805 & $0.026 *$ \\
\hline $\begin{array}{l}\text { Risk Planning \& } \\
\text { Identification (RPI) }\end{array}$ & 0.237 & $0.563 * * *$ & 5.435 & $0.006 * *$ \\
\hline Risk Analysis (RA) & 0.195 & $0.565 * * *$ & 5.288 & $0.007 * *$ \\
\hline Risk Mitigation (RM) & 0.054 & $0.566 * * *$ & 7.127 & $0.001 * *$ \\
\hline $\begin{array}{l}\text { Process Improvement \& } \\
\text { Integration (PII) }\end{array}$ & 0.190 & $0.596 * * *$ & 7.132 & $0.001 * *$ \\
\hline $\begin{array}{l}\text { Project Management Process } \\
\text { (PMP) }\end{array}$ & $0.361 *$ & $0.629 * * *$ & 5.695 & $0.005 * *$ \\
\hline Technology $(\mathrm{T})$ & $0.720 * * *$ & $0.546 * * *$ & 3.595 & $0.032 *$ \\
\hline
\end{tabular}


Table 6. Comparison of regression coefficients between two sub-groups of Requirement Uncertainty

\begin{tabular}{|c|c|c|c|c|}
\hline RM-CMM constructs & $\begin{array}{c}\text { Project Performance } \\
\text { (Low Requirement } \\
\text { Uncertainty, N1=65) }\end{array}$ & $\begin{array}{c}\text { Project Performance } \\
\text { (High Requirement } \\
\text { Uncertainty, N2=40) }\end{array}$ & $\mathrm{F}$ & $\begin{array}{c}\text { Level of } \\
\text { Significance }\end{array}$ \\
\hline Organizational Culture (OC) & $0.449 * * *$ & 0.057 & 1.169 & 0.315 \\
\hline Stakeholder Coalition (SC) & $0.515^{* * *}$ & $0.569 * * *$ & 0.124 & 0.895 \\
\hline Leadership (L) & $0.360 * *$ & $0.590 * * *$ & 0.234 & 0.792 \\
\hline $\begin{array}{l}\text { Organization Structure \& } \\
\text { Support (OSS) }\end{array}$ & $0.478 * * *$ & $0.498 * *$ & 0.095 & 0.521 \\
\hline $\begin{array}{l}\text { Risk Planning \& } \\
\text { Identification (RPI) }\end{array}$ & $0.447 * * *$ & 0.111 & 3.343 & $0.039 *$ \\
\hline Risk Analysis (RA) & $0.487 * * *$ & -0.011 & 4.820 & $0.010^{*}$ \\
\hline Risk Mitigation (RM) & $0.391 * *$ & 0.057 & 2.650 & 0.076 \\
\hline $\begin{array}{l}\text { Process Improvement \& } \\
\text { Integration (PII) }\end{array}$ & $0.427 * * *$ & 0.044 & 3.421 & $0.037^{*}$ \\
\hline $\begin{array}{l}\text { Project Management Process } \\
\text { (PMP) }\end{array}$ & $0.457 * * *$ & $0.579 * * *$ & 0.142 & 0.868 \\
\hline Technology (T) & $0.641 * * *$ & $0.555 * * *$ & 1.136 & 0.325 \\
\hline
\end{tabular}

$* * * \mathrm{p}<0.001,{ }^{* *} \mathrm{p}<0.01,{ }^{*} \mathrm{p}<0.05$

Table 7. The average score of RM-CMM constructs

\begin{tabular}{|c|c|c|c|}
\hline Construct & Mean & Standard Deviation & Rank \\
\hline \multicolumn{4}{|l|}{ I. Organization Capabilities for "Robustness": } \\
\hline 1.Organization Culture & 3.26 & 0.67 & 6 \\
\hline 2.Stakeholders Coalition & 3.40 & 0.59 & 2 \\
\hline 3.Leadership & 3.37 & 0.73 & 3 \\
\hline 4.Organization Structure and Support & 3.48 & 0.75 & 1 \\
\hline \multicolumn{4}{|l|}{$\begin{array}{l}\text { II. Process, Systems and Technology } \\
\text { Capabilities for "Security": }\end{array}$} \\
\hline 5.Risk Planning and Identification & 2.89 & 0.93 & 8 \\
\hline 6.Risk Analysis & 2.76 & 1.04 & 10 \\
\hline 7.Risk Mitigation & 2.91 & 1.04 & 7 \\
\hline 8.Process Integration and Improvement & 2.80 & 1.05 & 9 \\
\hline 9.Project Management Process & 3.36 & 0.84 & 5 \\
\hline 10.Technology & 3.36 & 0.83 & 4 \\
\hline
\end{tabular}

The results suggests that PMP and T should also be in a higher level as they are no less effective in higher complex and uncertain projects. They also constitute an integral part of "robustness" to deal with external and unpredictable risks.

\subsection{Current level of RM capability maturity}

The final CoPS-RM-CMM constructs and defining items and their perceived application in reference CoPS projects according to the respondents are summarized in Table A. 2 of the appendix. The mean and standard deviation are based on the 133 survey respondents' returns. For mean values that are above 3.6 (high to very high) and below 3.0 (medium), they are highlighted in asterisk* and italic respectively.

\subsection{Analysis of CoPS-RM-CMM influencing items}

The maturity level of each of the ten CoPS-RM-CMM constructs was calculated (ref. Table A.2), as shown in Table 7 , by taking the average of scores of all the usable survey returns. The ranking of the constructs is also shown. The highest construct is Organization Structure and Support (3.48), and the lowest is Risk Analysis (2.76). The weaker capability areas that scored less than 3.0 (medium applicability) are highlighted in italic.

From Table 7, we see that the ten maturity constructs can be divided into two groups. The higher maturity level $(>3.0)$ constructs include Organization Structure and Support, Technology, Stakeholder Coalition, Leadership, Project Management Process, and Organization Culture. The scores of this group are between 3.2 and 3.5. This group clustered together representing the organizational capabilities needed to deal with robustness issues and 
emergent risks. The overall score of this group is relatively high but not high enough in the case of Asian CoPS producers or implementers, when applying the "soft" risk management items for complex projects. There is still room for improvement in organizational robustness for the mainly Singapore based respondents involving in implementing complex projects. The same advice may be given to other non-Japanese Asian project-based enterprises.

The low maturity level (mean score<3.0) construct areas are more glaring and they are mainly RM process and systems related capabilities including Risk Planning and Identification, Risk Analysis, Risk Mitigation, and Process Integration and Improvement. This implies that RM processes and associated systems are the weak-links among Singapore and other Asian (non-Japanese)-based CoPS implementers. From the above analysis, we can derive that these system and process based capabilities are necessary but not sufficient conditions for a highly mature risk management. However, these hard capabilities are likely to provide the "security" foundation to build and support the soft capabilities to ensure organizational "robustness". Another interesting point we found is that RM process constructs have larger standard deviation than other constructs. It means there are big differences between CoPS providers in RM process maturity.

The systems based and weaker items (score<3.0) are extracted and shown in Table 8. Asian CoPS implementers would need to focus on these items in order to improve their overall RM capability maturity and project performance levels. The areas that need to be improved would include: Building formal RM processes; training and personal development on risk management systems and processes; continual development of RM capabilities in risk parameters definition and identification; RM responsibility and ownership assignment; use of external risk consultants; risk categorization by areas and events; prioritization of risk events; quantitative risk modeling and analysis including probability-impact analysis; setting aside contingency allowances for specific predictable risk and management reserves for unforeseen emergent risk; considering cost-effectiveness and benefits of holistic RM; allocating adequate resources for implementation of risk mitigation plans; residual risk monitoring and control; integration of RM process with other PM processes; data quality for RM; use of risk report; risk management performance metrics; process improvement and benchmarking best practices; RM information system; and integrated project performance measurement/control system (including Earned Value Method).

\section{Opinions on Asian CoPS Capabilities and Risk Management}

The questionnaire has been extended to survey Asian respondents' responses on Asian CoPS capabilities over a list of suggestions or opinions. For items measuring the concurrence to these opinions on Asian CoPS capabilities, the five scales used are " $1=$ strongly disagree", " $2=$ disagree", " $3=$ neutral", " $4=$ agree" and " $5=$ strongly agree".

The results of responses on Asian CoPS capabilities are shown in Table 9. The respondents agree with Opinion 3 most strongly that "Confucian culture and 'Face-saving' mindset is a major hindrance in achieving high level of performance by Asian CoPS providers". Such mindset may adversely undermine openness and communication effectiveness and hence organizational robustness in risk management. The second challenge is Opinion 2 that "Asian CoPS producers are generally weak in complex project/program management including Risk Management". The third is Opinion 4: "Asian CoPS project teams are less capable of 'self-organizing' and innovative as they prefer taking instructions from above". The fourth is Opinion 2e "Asian CoPS producers are generally weak in International business practices (e.g. legal, contracting, financing...)". The survey results suggest Asian CoPS producers should put more effort on the following areas: build a more open communication culture; improve project/program management capabilities, including risk management; improve the self-organization abilities of project teams to deal with the challenge of complexity more effectively; accumulate experience in and improve international business practices (e.g. legal, contracting, financing...).

Further comments on Asian CoPS capabilities by respondents show that there is an acknowledgement that there is a gap between Asian and Western CoPS capabilities, and there is an urgent need to learn from advanced Western best practices in system approaches to complex project management including risk management. One important reason of lagging behind for Asian is lack of CoPS exposure and experiences. As one respondent says "Asian countries don't have the necessary skills as compared to western countries where generally they have 20 years of experience at the senior level to manage such large and complex projects".

Table 8. Lower capability maturity items (Score < 3.0)

\begin{tabular}{cc}
\hline Item & Mean Maturity Level \\
\hline SC7 & 2.68 \\
OSS8 & 2.71 \\
RPI2 & 2.91 \\
RPI3 & 2.70 \\
RPI7 & 2.45 \\
RA1 & 2.77 \\
RA2 & 2.83 \\
RA3 & 2.95 \\
RA4 & 2.17 \\
RA5 & 2.77 \\
RM3 & 2.77 \\
RM4 & 2.92 \\
RM5 & 2.93 \\
RM6 & 2.88 \\
PII1 & 2.81 \\
PII2 & 2.80 \\
PII4 & 2.70 \\
PII5 & 2.90 \\
PII6 & 2.68 \\
PII8 & 2.66 \\
PII9 & 2.50 \\
PMP4 & 2.77 \\
\hline
\end{tabular}


Table 9. Reponses on Asian CoPS capability

\begin{tabular}{|c|c|c|c|}
\hline Opinions & No. of responses & Mean score & Ranking \\
\hline $\begin{array}{l}\text { 1. Asian CoPS producer companies have not been } \\
\text { able to make any headway in the Western markets }\end{array}$ & 124 & 3.07 & 6 \\
\hline \multicolumn{4}{|l|}{$\begin{array}{l}\text { 2. Asian CoPS producers are generally weak in the } \\
\text { following areas (a-f) which become major risk areas: }\end{array}$} \\
\hline $\begin{array}{l}\text { a) Project/program management including Risk } \\
\text { Management }\end{array}$ & 123 & 3.24 & 2 \\
\hline b) Systems Engineering/Design & 122 & 2.93 & 9 \\
\hline c) International Procurement & 121 & 2.95 & 8 \\
\hline d) Major Equipment Manufacturing & 123 & 3.08 & 5 \\
\hline $\begin{array}{l}\text { e) International business practices (e.g. legal, } \\
\text { contracting, financing...) }\end{array}$ & 122 & 3.13 & 4 \\
\hline f) In making institutional arrangements & 119 & 3.05 & 7 \\
\hline $\begin{array}{l}\text { 3. Confucian culture and "Face-saving" mindset is a } \\
\text { major hindrance in achieving high level of } \\
\text { performance by Asian CoPS providers }\end{array}$ & 123 & 3.28 & 1 \\
\hline $\begin{array}{l}\text { 4. Asian CoPS project teams are less capable of } \\
\text { "self-organizing" and innovative as they prefer } \\
\text { taking instructions from above. }\end{array}$ & 124 & 3.17 & 3 \\
\hline
\end{tabular}

Another major concern is cultural differences. It is believed that Western culture are more open and confrontational, while Asian often have guarded and behind the scene action to get consensus. For example, one respondent states "Western countries practice lower power distance, while Asians practice high power distance. That allows every Westerner (employee) has a right to say while only bosses have a right to say in Asian societies". Regarding the information sharing, one respondent believes that "Western people are more open-minded to share information and are willing to challenge and admit mistakes. But Eastern people are more conservative. They keep good information as private treasure and bad information as a shame. They want to save face until the last minute which is very risky itself."

The third concern is lack of RM practices. RM has not been well recognized by many Asian companies. As one respondent stated the difference: "from my experience working with an American company they are completely focused on Risk Management and European Insurers also want this practice used properly".

Some respondents think that Asian is making progress in CoPS capabilities. As one respondent stated: "With the current phenomenon of globalization, the adoption of international standards/best practices has narrowed the gaps/differences". A senior European project manager worked on Singapore's mass rapid transit (MRT) railway systems said that Singapore has closed the gap with Western countries in complex railway system development.

\section{Contribution and Discussion}

This work contributes to the management of CoPS projects by proving there is a link between RM maturity level and project success, and a contingency approach is needed for managing risks in CoPS. Compared with Raz et al. (2002), our result is more comprehensive. Our result validates their finding that $\mathrm{RM}$ is more useful in projects with higher technological uncertainty. Our new contribution is that we also show that RM process is more useful in projects with higher complexity, but less effective in projects with higher requirement uncertainty. In such situation, a formal RM process does not help because it is hard to conduct accurate risk analysis and control. Instead, organization factors such as organization coalition and organization structure is more important to resolve risks related to requirement uncertainty.

This research also validates the basic structure of CoPS-RM-CMM model of Yeo and Ren (2009) that both security and robustness are needed for project success. Security is mainly used to deal with internal and predictable risks and robustness are mainly used to deal with emergent risks. However, the result suggests some modification to the definition of security and robustness: security related constructs include RM process, and robustness related constructs include organization and human factors, PM process and technology.

Recent research on complex projects supports the complementary effect of security and robustness on project performance. Gil and Tether (2011) show that design flexibility and risk management (mainly RM process) complement each other for managing the tension between efficiency and effectiveness. Design flexibility is supported by strong co-operation (an aspect of robustness), and could help achieve effectiveness in uncertain situations. Risk management process, a part of security, can help achieve efficiency, which is for predictable risks. Olausso and Berggren (2010) illustrated that it was critical to integrate and balance needs for formal organizational control with high levels of project flexibility in managing complexity and uncertainty in high-tech complex product development. Formal organizational control represents security and project flexibility, enabled by interactive communication and collective effort to handle changes, is 
a way to strengthen robustness. Osipova and Eriksson (2013) studied the effect of control-oriented and flexibility-oriented management styles on the effectiveness of Joint Risk Management (JRM) through two case studies. In the first case project, JRM was successful because a balance was achieved between the two management styles. However, in the second case project, too much control limited the flexibility and consequently jeopardized the benefit of JRM. The conclusion is that JRM requires both control mechanism to manage predictable risks and flexibility to cope with unforeseen risk, which resembles the principles of CoPSRM-CMM.

Our results identify RM process as a weak link for Asian CoPS providers. Other RM constructs are relatively better but there is still room for improvement. The responses about Asian CoPS capability reveal that a gap with Western CoPS providers is acknowledged, and one obstacle is lack of open communication about risk and lack of RM practices. So one way to improve the overall RM capability is to foster an open culture to discuss risks and promote a formal RM process.

\section{Conclusions and Future Work}

This paper evaluates risk management capability maturity level of CoPS projects against a general CoPS-RM-CMM. The model divides items of capability maturity into system- and process-based "security" and organizational "robustness" as necessary to deal with the challenges of complexity and uncertainty in managing complex projects and ensure their success. An Asian based survey was conducted to investigate the value of RM to project performance, and Asian (non-Japanese) CoPS implementers' perceived application of risk management practices, their strengths and weaknesses. The survey results reveal that balanced hard and soft capabilities to address both systems and behavioral requirements are needed. The systematic capability is necessary but not sufficient, as it must be complemented by soft capabilities to build robustness in risk awareness culture, leadership, stakeholder relationships, and organization structure and support. For different types of projects, different strategies should be used. When systems complexity and technological uncertainty increase, both robustness and security are needed, but for highly complex dynamic projects with requirement uncertainty, organizational robustness is more likely to be the deciding factor. From the survey results, Asian CoPS producers or implementers seem to have perceived weaknesses in systematic RM applications. Although cultural robustness is fair better, there are still rooms for improvement. We give suggestions on how to improve the weak areas.

This study has several limitations. First, it takes an Asian perspective. Interesting questions such as whether there are same relationship between RM maturity and project performance and a contingency approach in RM need to be explored. Our future work is conduct a western based survey and analyze the difference. Another thing is that our key finding such as RM process is not so effective when requirement uncertainty is high, need to be further explored. In-depth case studies under this situation would be very helpful to evaluate the finding.

\section{References}

Abednego, M. P. and Ogunlana, S. O. (2006). Good project governance for proper risk allocation in public-private partnerships in Indonesia. International Journal of Project Management, 24, 622-634.

Baccarini, D. (1996). The concept of project complexity a review. International Journal of Project Management, 14, 201-204.

Chapman, C. B. and Ward S. C. (2008). Developing and implementing balanced incentive and risk sharing contracts. Construction Management and Economics, 26, 659-669.

Chapman, C. B. and Ward, S. C, (2003). Project risk management: processes, techniques and insights, 2nd edition, Wiley, Chichester, UK.

Chapman, C. B. and Ward, S. C, (2011). How to Manage Project Opportunity and Risk - why uncertainty management can be a much better approach than risk management, 3rd edition (retitled), Wiley, Chichester, UK.

Chow, G. C., (1960). Tests of equality between sets of coefficients in two linear regressions, Econometrica, 28, 591-605.

Churchill, G. A. (1979). A paradigm for developing better measures of marketing constructs. Journal of Marketing Research, 16, 64-73.

Cortina, J. M. (1993). What is coefficient Cronbach alpha? An examination of the theory and applications. Journal of Applied Psychology, 78, 98-104.

Crawford, L. H. and Pollack, J. (2004). Hard and soft projects: a framework for analysis. International Journal of Project Management, 22, 645-653.

Crawford, L. H., Hobbs, J. B., and Turner J. R. (2005). Project categorization systems: aligning capability with strategy for better results. Project Management Institute, Pennsylvania.

De Meyer, A., Loch, C. H., and Pich M. H. (2002). Managing project uncertainty: from variation to chaos, Sloan Management Review, 43, 60-67.

Gil, N. and Tether, B. S. (2011). Project risk management and design flexibility: Analyzing a case and conditions of complementarity, Research Policy, 40, 415-428.

Hobday, M. (1998). Product complexity, innovation and industrial organization. Research Policy, 6, 89-710.

Hobday, M. and Rush, H. (1999). Technology management in complex product systems (CoPS) ten questions answered, International Journal on Technology Management, 17, 618-638.

Ivory, C. and Alderman, N. (2005). Can project management learn anything from studies of failure in complex systems? Project Management Journal, 36, 5-16.

Kerzner, H. (2009). Project Management: A Systems Approach to Planning, Scheduling, and Controlling. 10th edition, John Wiley, New York.

Lai, C. (2010). Research on non-linear dynamics correcting mechanism of Complex Products and System. Advanced Materials Research, 113-116, 679684.

Marrewijk, A. V., Clegg, S. R., Pitsis, T. S., and Veenswijk, M. (2008). Managing public-private megaprojects: Paradoxes, complexity, and project design. International Journal of Project Management, 26, 591-600.

McDonald, R. P. (1985). Factor analysis and related methods. Lawrence Erlbaum Associates, Hillsdale, NJ. 
Miller, R. and Lessard, D. R. (2000). The Strategic Management of Large Engineering Projects. MIT Press, Cambridge, MA.

Morris, P. W. G. (1990). The strategic management of projects. Technology in Society, 12, 197-215.

Müllera, R. and Turner, J. R. (2007). Matching the project manager's leadership style to project type, International Journal of Project Management, 25, 2132.

Olausson, D. and Berggren, C. (2010). Managing uncertain, complex product development in high-tech firms: in search of controlled flexibility. $R \& D$ Management, 40, 383-399.

Olsson, R. (2007). In search of opportunity management: Is the risk management process enough? International Journal of Project Management, 25, 745-752.

Osipova, E. and Eriksson, P. E. (2013). Balancing control and flexibility in joint risk management: Lessons learned from two construction projects. International Journal of Project Management, 31, 391-399.

Oyewobi, L. O., Ibrahim, A. D., and Ganiyu, B. O. (2012). Evaluating the Impact of Risk on Contractor's Tender Figure in Public Buildings Projects in Northern Nigeria. Journal of Engineering, Project, and Production Management, 2(1), 2-13.

Paulk, M. C., Curtis, B., Chrissis, M. B., and Weber, C.V. (1993). Capability Maturity Model for Software, version 1.1. Software Engineering Institute (SEI), Technical Report no. CMU/SEI-93-TR-24.

Project Management Institute (2008). A Guide to the Project Management Body of Knowledge. Project Management Institute, Pennsylvania.

Raz, T., Shenhar, A. J., and Dvir, D. (2002). Risk management, project success, and technological uncertainty. R\&D Management, 32, 101-109.

Ren, Y. and Yeo, K. T. (2006). Research challenges on Complex Product Systems Innovation, Journal of the Chinese Institute of Industrial Engineers, 23, 519-529.

Rosenberg, N. (1976). Perspectives on technology. Cambridge University Press, Cambridge.

Sauser, B. J., Reilly, R. R., and Shenhar, A. J. (2009). Why projects fail? How contingency theory can provide new insights - A comparative analysis of NASA`s Mars Climate Orbiter loss. International Journal of Project Management, 27, 665-679.

Shenhar, A. J. (1998). From theory to practice: Toward a typology of project management styles, IEEE Transactions on Engineering Management. 45, 33-48.

Shenhar, A. J. and Dvir, D. (2007). Reinventing project management: the diamond approach to successful growth and innovation, Harvard Business School Press, Boston.

Software Engineering Institute (SEI) (2002). Capability Maturity Model ${ }^{\circledR}$ Integration (CMMISM) Staged Representation, Version 1.1. Technical Report no. CMU/SEI-2002-TR-012.

Voetsch, R. J. and Cioffi, D. F. (2003). The current state of project risk management practices among risksensitive project management professionals, Risk Management Newsletter, 5.

Ward, S. C. and Chapman, C. B. (2008). Stakeholders and uncertainty management in projects, Construction Management and Economics, 26, 563-577.

Whittaker, B. (1999). What went wrong? Unsuccessful information technology projects, Information Management and Computer Security, 7, 23-29.
Williams, T. M. (1999). The need for new paradigms for complex projects, International Journal of Project Management, 17, 269-273.

Wood, R. E. (1986). Task complexity: definition of the construct. Organizational Behavior and Human Decision Processes, 37, 60-82.

Xia, W. and Lee, G. (2005). Complexity of information systems development projects: conceptualization and measurement development. Journal of Management Information System, 22, 45-83.

Yeo, K. T. and Ren, Y. (2009). Risk Management Capability Maturity Model for Complex Product System (CoPS) projects, Systems Engineering, 12, 275-294.

Yeo, K. T. (1995). Strategy for risk management through problem framing in technology acquisition. International Journal of Project Management, 13, 219-224.

Zhang, W. and Igel, B. (2001). Managing the product development of China's SPC switch industry as an example of CoPS. Technovation, 21, 361-368.

Zwikael, O. and Ahn, M. (2011). The effectiveness of Risk Management: an analysis of Project Risk Planning across industries and countries, Risk Analysis, 31, 25-37.

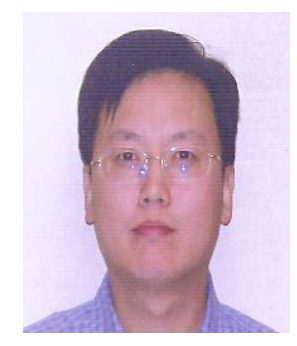

Yingtao Ren is a Senior Research Scientist of the R\&D department of Manhattan Associates, inc., Atlanta, USA. He obtained his Ph.D in Industrial and Systems Engineering from University of Southern California in 2011. He has published more than 10 papers in Transportation Science, Systems Engineering Journal, Computers and Operations Research, and international conference proceedings. His research interests include project risk management, uncertainty management, and transportation optimization.

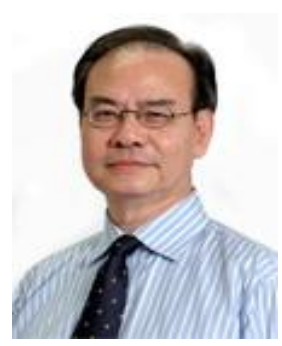

Khim Teck Yeo is an Associate Professor in School of Mechanical and Aerospace Engineering, Nanyang Technological University, Singapore. $\mathrm{He}$ was formerly establishing Head, Division of Systems and Engineering Management. He has been a visiting scholar to Sloan School of Management, MIT, Boston. He has over 130 publications in refereed international journals and conference proceedings. He has also served as a consultant and trainer in project and systems management to many large corporations such as AT\&T, JEL, Philips, Infineon, HP/Compaq, etc.

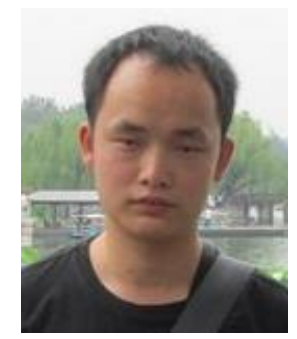

Yingju Ren is a Research Engineer in the Institute of Nuclear and New Energy Technology, Tsinghua University, Beijing, China. He obtained his Bachelor's degree in Thermal Energy and Power Engineering from Liaoning Technical University in 2008. His research interests include project management, Computed-Aided Design, and engineering management. 


\section{Appendix}

Table A.1. The measuring items of RM-CMM constructs

\begin{tabular}{|c|c|}
\hline Construct & Items \\
\hline \multirow{7}{*}{$\begin{array}{l}\text { 1.Organization Culture } \\
\text { (OC) }\end{array}$} & OC1: We were aware of the risk and uncertainty facing the project \\
\hline & OC2: We had open communication on project risks within project team \\
\hline & OC3: We had a proactive risk management culture \\
\hline & $\begin{array}{l}\text { OC4: Team members felt free to try innovative ideas, and high tolerance to people make } \\
\text { mistakes }\end{array}$ \\
\hline & $\begin{array}{l}\text { OC5: Team members are allowed to challenge and seek changes to stated underlying } \\
\text { assumptions in strategy, decision and actions when taking a "Big Picture". }\end{array}$ \\
\hline & OC6: We also identified \& exploited opportunities under uncertainty \\
\hline & OC7: We used Informal methods to complement formal methods in risk management \\
\hline \multirow{9}{*}{$\begin{array}{l}\text { 2. Stakeholders } \\
\text { Coalition (SC) }\end{array}$} & SC1: We identified and involved relevant stakeholders in the risk management process \\
\hline & SC2: There was an agreed project vision among all stakeholders \\
\hline & SC3: We maintained good relationship with project's key customer/user \\
\hline & SC4: We maintained good relationship with project's key suppliers \\
\hline & SC5: Both formal and informal methods were used to build relationship and coalition \\
\hline & SC6: We had long-term arrangements (e.g. partnership) with key stakeholders \\
\hline & SC7: We had risk/reward sharing arrangements with key contractors \\
\hline & $\begin{array}{l}\text { SC8: We established a collaboration environment for free and open communication of risk } \\
\text { among stakeholders }\end{array}$ \\
\hline & SC9: We communicated with affected parties and address their concerns \\
\hline \multirow{6}{*}{ 3. Leadership (L) } & L1: Exercised democratic management style \\
\hline & L2: Empowered project team members \\
\hline & L3: Created the context for self-organization/decision-making at team levels \\
\hline & L4: Spent to motivate \& energize team members \\
\hline & L5: Strong in networking abilities \& making strategic alliances \& coalition arrangements \\
\hline & L6: Had good rapport with Project Sponsor \& corporate senior management \\
\hline \multirow{8}{*}{$\begin{array}{l}\text { 4. Organization } \\
\text { Structure and Support } \\
\text { (OSS) }\end{array}$} & OSS1: Projectised organization: (Circle: Loose matrix/strong matrix/ projectised ) \\
\hline & OSS2: Teamwork was emphasized within the company \\
\hline & OSS3: Teamwork was emphasized across participating companies \\
\hline & OSS4: There was a sense of "ownership" and strong team identify \\
\hline & OSS5: The project got top management support \\
\hline & OSS6: Senior management supported risk management activities/initiatives \\
\hline & $\begin{array}{l}\text { OSS7: Senior management provided adequate resources for performing risk management } \\
\text { activities }\end{array}$ \\
\hline & OSS8: We had periodic training and personal development on project risk management \\
\hline \multirow{7}{*}{$\begin{array}{l}\text { 5. Risk Planning and } \\
\text { Identification } \\
\text { (RPI) }\end{array}$} & RPI1: We defined risk sources/categories/events/lists of the project (please circle) \\
\hline & $\begin{array}{l}\text { RPI2: Risk parameters such as risk probability, risk consequence, and thresholds to trigger } \\
\text { management activities were defined }\end{array}$ \\
\hline & $\begin{array}{l}\text { RPI3: We assigned responsibility and authority for performing the risk management process, } \\
\text { i.e. assigning a risk manager or equivalent }\end{array}$ \\
\hline & $\begin{array}{l}\text { RPI4: We identified a broad range of risks, including internal/external, technical/ non-technical } \\
\text { risks (please circle) }\end{array}$ \\
\hline & $\begin{array}{l}\text { RPI5: We learned \& documented lessons from previous projects and utilize historical } \\
\text { information }\end{array}$ \\
\hline & RPI6: We involved key project/function members in risk identification \\
\hline & RPI7: We used external consultants/specialists in risk identification \\
\hline
\end{tabular}


Table A.1. The measuring items of RM-CMM constructs(continue)

\begin{tabular}{|c|c|}
\hline Construct & Items \\
\hline \multirow{6}{*}{ 6. Risk Analysis (RA) } & $\begin{array}{l}\text { RA1: We evaluated the identified risks using the defined risk parameters such as probability (P) } \\
\text { and impact (I) }\end{array}$ \\
\hline & $\begin{array}{l}\text { RA2: We categorized and grouped risks into risk categories for the purpose of efficient } \\
\text { handling }\end{array}$ \\
\hline & RA3: We prioritized risk events based on their risk exposure/severity (Probability x Impact) \\
\hline & RA4: We conducted quantitative risk analysis (e.g., Monte Carlo simulation analysis) \\
\hline & RA5: We set aside management reserves (outside budget) for unexpected risk events \\
\hline & $\begin{array}{l}\text { RA6: We set aside contingency allowances (within budget) for potential variations of specific } \\
\text { risk items. }\end{array}$ \\
\hline \multirow{5}{*}{ 7. Risk Mitigation (RM) } & RM1: We developed risk response plans for the most critical risks to the project \\
\hline & $\begin{array}{l}\text { RM2: We used a variety of risk mitigation strategies (please circle: avoidance, transfer to 3rd } \\
\text { party, mitigation/reduction, and acceptance with or without contingency) }\end{array}$ \\
\hline & RM3: We considered the cost-to-benefit ratio of implementing the risk mitigation plan \\
\hline & $\begin{array}{l}\text { RM4: We determined and assigned risk ownership to appropriate stakeholders and project } \\
\text { functions }\end{array}$ \\
\hline & $\begin{array}{l}\text { RM5: We implemented risk mitigation plans when monitored risks exceed the defined } \\
\text { thresholds }\end{array}$ \\
\hline \multirow{10}{*}{$\begin{array}{l}\text { 8. Process Integration } \\
\text { and Improvement (PII) }\end{array}$} & RM6: Risk mitigation actions and residual risks were monitored and controlled \\
\hline & $\begin{array}{l}\text { PII1: Risk management process was adequately integrated with the other project management } \\
\text { processes }\end{array}$ \\
\hline & PII2: We had a formal risk management process \\
\hline & $\begin{array}{l}\text { PII3: We identified and managed risks continuously through all phases of the project's life } \\
\text { cycle }\end{array}$ \\
\hline & PII4: Data for risk analysis and reporting were of good quality \\
\hline & PII5: Risk report was used for decision making by senior management \\
\hline & PII6: We measured the effectiveness of risk management with performance metrics \\
\hline & PII7: We conducted post-project review and documented lessons learned \\
\hline & $\begin{array}{l}\text { PII8: We collected process improvement information and benchmarked our risk management } \\
\text { practices with industry best practices }\end{array}$ \\
\hline & $\begin{array}{l}\text { PII9: We had a risk management information system containing risk database, checklist, and } \\
\text { risk status report }\end{array}$ \\
\hline \multirow{8}{*}{$\begin{array}{l}\text { 9. Project Management } \\
\text { Process (PMP) }\end{array}$} & PMP1: We had formal project management processes \\
\hline & PMP2: We had adequate front-end project planning \\
\hline & PMP3: We had a project management information system (PMIS) \\
\hline & PMP4: We had an integrated project performance measurement/control system \\
\hline & (e.g. using Earned Value Method) \\
\hline & PMP5: We had effective change management procedures \\
\hline & PMP6: We ensured personnel continuity in the project \\
\hline & PMP7: We used latest IT/Internet to facilitate information exchange and communication \\
\hline \multirow{6}{*}{ 10. Technology $(\mathrm{T})$} & T1: We captured user requirements correctly with minimum design change \\
\hline & $\begin{array}{l}\text { T2: We have strong technological development programs, but conservative in new technology } \\
\text { applications (Adopt mainly proven technology) }\end{array}$ \\
\hline & T3: We aligned the use of advanced technology with business development strategies \\
\hline & T4: We had strong system engineering and integration capability \\
\hline & T5: We had strong technical infrastructure and competence (e.g. use of CAD/CAE software) \\
\hline & T6: There was a high degree of user/customer involvement/inputs in design \\
\hline
\end{tabular}


Table A.2. Applicability of RM capability maturity items (practices) in reference projects (Scale 1 to 5 in Applicability: 1-Not applicable, 2-Low, 3-Medium, 4-High, \& 5-Very High)

\begin{tabular}{|c|c|c|c|}
\hline Construct & Items & Mean & Standard Deviation \\
\hline \multirow{7}{*}{ 1.Organization Culture (OC) } & $\mathrm{OC} 1$ & $3.63 *$ & 0.89 \\
\hline & $\mathrm{OC} 2$ & 3.55 & 1.09 \\
\hline & OC3 & 3.37 & 1.12 \\
\hline & OC4 & 3.02 & 0.93 \\
\hline & OC5 & 3.08 & 0.91 \\
\hline & OC6 & 3.11 & 0.90 \\
\hline & OC7 & 3.05 & 0.95 \\
\hline \multirow{9}{*}{ 2. Stakeholders Coalition (SC) } & $\mathrm{SC} 1$ & 3.2 & 1.11 \\
\hline & $\mathrm{SC} 2$ & 3.46 & 0.88 \\
\hline & SC3 & $3.91 *$ & 0.75 \\
\hline & $\mathrm{SC} 4$ & $3.65^{*}$ & 0.85 \\
\hline & SC5 & 3.53 & 0.83 \\
\hline & SC6 & 3.53 & 0.97 \\
\hline & SC7 & 2.68 & 1.03 \\
\hline & $\mathrm{SC} 8$ & 3.15 & 0.97 \\
\hline & SC9 & 3.46 & 0.87 \\
\hline \multirow{6}{*}{ 3. Leadership (L) } & L1 & 3.30 & 0.96 \\
\hline & L2 & 3.41 & 0.83 \\
\hline & L3 & 3.33 & 0.80 \\
\hline & L4 & 3.23 & 0.98 \\
\hline & L5 & 3.29 & 0.92 \\
\hline & L6 & $3.62 *$ & 0.85 \\
\hline \multirow{8}{*}{$\begin{array}{l}\text { 4. Organization Structure and Support } \\
\text { (OSS) }\end{array}$} & OSS1 & $3.83^{*}$ & 1.04 \\
\hline & OSS2 & $3.69 *$ & 0.88 \\
\hline & OSS3 & 3.35 & 0.90 \\
\hline & OSS4 & 3.53 & 0.99 \\
\hline & OSS5 & $3.89 *$ & 0.91 \\
\hline & OSS6 & 3.56 & 1.05 \\
\hline & OSS7 & 3.26 & 1.13 \\
\hline & OSS8 & 2.71 & 1.17 \\
\hline \multirow{7}{*}{$\begin{array}{l}\text { 5. Risk Planning and Identification } \\
\text { (RPI) }\end{array}$} & RPI1 & 3.00 & 1.15 \\
\hline & RPI2 & 2.91 & 1.15 \\
\hline & RPI3 & 2.70 & 1.17 \\
\hline & RPI4 & 3.01 & 1.19 \\
\hline & RPI5 & 3.04 & 1.08 \\
\hline & RPI6 & 3.16 & 1.09 \\
\hline & RPI7 & 2.45 & 1.27 \\
\hline \multirow{6}{*}{ 6. Risk Analysis (RA) } & RA1 & 2.77 & 1.33 \\
\hline & RA2 & 2.83 & 1.26 \\
\hline & RA3 & 2.95 & 1.33 \\
\hline & RA4 & 2.17 & 1.20 \\
\hline & RA5 & 2.77 & 1.17 \\
\hline & RA6 & 3.08 & 1.18 \\
\hline
\end{tabular}


Yingtao Ren, Khim Teck Yeo, and Yingju Ren

Table A.2. Applicability of RM capability maturity items (practices) in reference projects(continue) (Scale 1 to 5 in Applicability: 1-Not applicable, 2-Low, 3-Medium, 4-High, \& 5-Very High)

\begin{tabular}{lccc}
\hline \multicolumn{1}{c}{ Construct } & Items & Mean & Standard Deviation \\
\hline \multirow{4}{*}{ 7. Risk Mitigation (RM) } & RM1 & 3.06 & 1.17 \\
& RM2 & 3.10 & 1.18 \\
& RM3 & 2.77 & 1.12 \\
& RM4 & 2.92 & 1.15 \\
& RM5 & 2.93 & 1.15 \\
& RM6 & 2.88 & 1.21 \\
& PII1 & 2.81 & 1.14 \\
& PII2 & 2.80 & 1.28 \\
8. Process Integration and Improvement & PII3 & 3.01 & 1.25 \\
(PII) & PII4 & 2.70 & 1.16 \\
& PII5 & 2.90 & 1.25 \\
& PII6 & 2.68 & 1.21 \\
& PII7 & 3.19 & 1.16 \\
& PII8 & 2.66 & 1.12 \\
& PII9 & 2.50 & 1.20 \\
9. Project Management Process (PMP) & PMP1 & $3.71 *$ & 1.03 \\
& PMP2 & $3.64 *$ & 0.96 \\
& PMP3 & 3.21 & 1.12 \\
& PMP4 & 2.77 & 1.13 \\
& PMP5 & 3.29 & 1.12 \\
& PMP6 & 3.35 & 1.07 \\
& PMP7 & 3.52 & 1.06 \\
& T1 & 3.30 & 0.90 \\
& T2 & 3.31 & 1.00 \\
& T3 & 3.26 & 0.92 \\
& T4 & 3.47 & 1.08 \\
& T5 & 3.47 & 1.05 \\
\hline
\end{tabular}

